\title{
Identification of Genetic Modules Mediating the Jekyll and Hyde Interaction of Dinoroseobacter shibae with the Dinoflagellate Prorocentrum minimum
}

\begin{abstract}
Hui Wang ${ }^{1 \dagger}$, Jürgen Tomasch ${ }^{1 \dagger}$, Victoria Michael2, Sabin Bhujü ${ }^{3}$, Michael Jarek ${ }^{3}$, Jörn Petersen ${ }^{2}$ and Irene Wagner-Döbler ${ }^{1 *}$
\end{abstract}

${ }^{1}$ Helmholtz-Centre for Infection Research, Microbial Communication, Braunschweig, Germany, ${ }^{2}$ German Collection of Microorganisms and Cell Cultures, Microbial Ecology and Diversity Research, Braunschweig, Germany, ${ }^{3}$ Helmholtz-Centre for Infection Research, Genome Analytics, Braunschweig, Germany

OPEN ACCESS

Edited by:

Rex Malmstrom

DOE Joint Genome Institute, USA

Reviewed by:

Rebecca Case,

University of Alberta, Canada

Shady A. Amin,

University of Washington, USA

*Correspondence:

Irene Wagner-Döbler

irene.wagner-doebler@helmholtz-

hzi.de

tThese authors have contributed equally to this work.

Specialty section:

This article was submitted to

Aquatic Microbiology,

a section of the journal

Frontiers in Microbiology

Received: 28 July 2015 Accepted: 30 October 2015 Published: 13 November 2015

Citation:

Wang H, Tomasch J, Michael V,

Bhuju S, Jarek M, Petersen J and Wagner-Döbler I (2015) Identification of Genetic Modules

Mediating the Jekyll and Hyde Interaction of Dinoroseobacter shibae with the Dinoflagellate Prorocentrum minimum. Front. Microbiol. 6:1262. doi: 10.3389/fmicb.2015.01262
The co-cultivation of the alphaproteobacterium Dinoroseobacter shibae with the dinoflagellate Prorocentrum minimum is characterized by a mutualistic phase followed by a pathogenic phase in which the bacterium kills aging algae. Thus it resembles the "Jekyll-and-Hyde" interaction that has been proposed for other algae and Roseobacter. Here, we identified key genetic components of this interaction. Analysis of the transcriptome of $D$. shibae in co-culture with $P$. minimum revealed growth phase dependent changes in the expression of quorum sensing, the CtrA phosphorelay, and flagella biosynthesis genes. Deletion of the histidine kinase gene cckA which is part of the CtrA phosphorelay or the flagella genes fliC or flgK resulted in complete lack of growth stimulation of P. minimum in co-culture with the D. shibae mutants. By contrast, pathogenicity was entirely dependent on one of the extrachromosomal elements of D. shibae, the $191 \mathrm{~kb}$ plasmid. The data show that flagella and the CtrA phosphorelay are required for establishing mutualism and prove a cell density dependent killing effect of $D$. shibae on $P$. minimum which is mediated by an unknown factor encoded on the $191 \mathrm{~kb}$ plasmid.

Keywords: Roseobacter, Dinoflagellate, pathogenicity, CtrA-phosphorelay, quorum sensing, symbiosis, type IV secretion system, plasmid

\section{INTRODUCTION}

Members of the Roseobacter clade within the Alphaproteobacteria often dominate bacterial communities associated to marine algae (Gonzalez et al., 2000; Riemann et al., 2000; Alavi et al., 2001; Allgaier et al., 2003; Tujula et al., 2010; Ankrah et al., 2014; Chen et al., 2015). Uncultivated lineages of the Roseobacter clade were shown to play different roles during successions induced by algal blooms in the North Sea (Teeling et al., 2012; Wemheuer et al., 2014; Voget et al., 2015). Interactions between roseobacters and marine algae can be mutualistic (Amin et al., 2015; Durham et al., 2015), pathogenic (Case et al., 2011; Fernandes et al., 2011; Paul and Pohnert, 2011; Gardiner et al., 2015), or shift between both (Seyedsayamdost et al., 2011b; Wang et al., 2014a). 
The Roseobacter strain Ruegeria sp. R11 was shown to induce bleaching of the macroalgae Delisea pulchra at elevated temperatures and when biosynthesis of quorum sensing (QS) inhibiting furanones by the algae was impaired (Case et al., 2011). Ruegeria sp. TM1040 and the heterotrophic dinoflagellate Pfiesteria piscicida display a mutualistic interaction, showing bacterial uptake of the algal osmolyte dimethylsulfoniopropionate (DMSP; Miller and Belas, 2004) and microalgal uptake of growth promoting factors produced by the bacteria (Geng and Belas, 2010). Bacterial motility controlled by the cell cycle regulator CtrA and the histidine kinase CckA has been shown to be important in this interaction (Miller and Belas, 2006). Interestingly, a so-called Roseobacter Motility Inducer (RMI) extracted from cell-free supernatants of this bacterial species showed algicidal effect against Tetraselmis striata and T. chuii (Sule and Belas, 2013). Ruegeria pomeroyi produces algicidal lactones which show an inhibitory effect against the fresh water alga Chlorella fusca (Riclea et al., 2012). An algicidal compound termed roseobacticide is produced by Phaeobacter inhibens BS107 in the presence of p-coumaric acid, a degradation product of lignin released by aging coccolithophores like Emiliania huxleyi (Seyedsayamdost et al., 2011a,b). P. inhibens also produces tropodithietic acid (TDA), an antibacterial compound whose production is controlled by QS (Berger et al., 2011). Thus, the relationship between the coccolithophore E. huxleyi and P. inhibens might shift from a mutualistic stage, where the bacteria protect the algae from other bacteria through the synthesis of TDA, to a pathogenic stage where algal lysis is induced by the roseobacticides. For the biosynthesis of roseobacticides in $P$. inhibens, three precursor molecules are needed, namely phenylacetic acid, a plant growth promoter synthesized by the bacterium, $p$-coumaric acid derived from aging alga, and cysteine derived from the algal osmolyte DMSP which can be used as a carbon source by the bacterium. Strikingly, while each of these molecules is beneficial in the mutualistic phase, they might be combined to make toxins in the pathogenic phase (Seyedsayamdost et al., 2014).

Our work on the interaction between Prorocentrum minimum, a dinoflagellate that is capable of photoautotrophic growth but also feeds on algal prey upon phosphorous and nitrogen limitation (Stoecker et al., 1997; Johnson, 2015), and the Roseobacter species Dinoroseobacter shibae has demonstrated that indeed these two organisms switch from a mutualistic to an antagonistic stage in co-culture (Wang et al., 2014a), thus resembling the "Jekyll and Hyde" interaction proposed for E. huxleyi and P. inhibens (Seyedsayamdost et al., 2011b). D. shibae has been shown to provide vitamins $B_{12}$ and $B_{7}$ to its algal host (Wagner-Döbler et al., 2010). Here, we started to investigate the genetic mechanisms underlying both the mutualistic and the antagonistic relationship. D. shibae harbors a complex $N$-acyl homoserine lactone (AHL) mediated QS system regulating phenotypic traits that might be important for the interaction with dinoflagellates, e.g., flagella and two type IV secretion systems (T4SS). The T4SS are located on the 191 and $126 \mathrm{~kb}$ sister plasmids, respectively (Patzelt et al., 2013). Recently, we have demonstrated that the CtrA phosphorelay, an important regulatory circuit in Alphaproteobacteria (Brilli et al., 2010), is integrated into the QS system of D. shibae and controls flagella biosynthesis as well as the synthesis of AHLs with a C14 side chain (Wang et al., 2014b).

Here, we investigated the transcriptome of $D$. shibae in coculture with $P$. minimum. Based on those findings we then studied how deletion mutants for key genes, e.g., the autoinducer synthase $l u x I_{1}$, the histidine kinase $c c k A$, genes from the flagella gene clusters as well as the complete $191 \mathrm{~kb}$ plasmid, changed the mutualistic or pathogenic phase of the co-culture between P. minimum and D. shibae.

\section{MATERIALS AND METHODS}

\section{Cultivation of Algae and Bacteria}

The axenic culture of Prorocentrum minimum CCMP 1329 used in this work was obtained from the Provasoli-Guillard National Center for Marine Algae and Microbiota (NCMA, formerly the Provasoli-Guillard National Center for Culture of Marine Phytoplankton, CCMP). CCMP 1329 was cultivated as previously described (Wang et al., 2014a). D. shibae DFL-12 strains (Table 1) were grown at $30^{\circ} \mathrm{C}$ and $160 \mathrm{rpm}$ in a chemically defined sea water medium (SWM) supplemented with $5 \mathrm{mM}$ succinate, prepared as described previously (Tomasch et al., 2011). The cocultures of $P$. minimum with $D$. shibae strains were prepared as previously described (Wang et al., 2014a). In brief, bacterial cells where added up to a final density of $10^{7}$ cells $/ \mathrm{ml}$ to the culture of $P$. minimum immediately after subculturing the dinoflagellate in fresh L1 medium lacking vitamin $B_{12}$ with an initial density of approximately 2000 cells $/ \mathrm{ml}$. The co-culture was grown in $100 \mathrm{ml}$ batches in $300 \mathrm{ml}$ Erlenmeyer flasks at $22^{\circ} \mathrm{C}$ under a $12: 12 \mathrm{~h}$ lightdark cycle with a light intensity of about $40 \mu \mathrm{mol}$ photons $\mathrm{m}^{-2}$ $s^{-1}$. Growth of algae and bacteria was followed by cell counting using a BD FACS Canto flow cytometer (BD Biosciences, San Jose, CA, USA), according to the methods described previously (Wang et al., 2014a). Strains of D. shibae used in this study are listed in Table 1. All cultivations were performed in triplicates.

\section{Sampling}

All cultures were monitored for 36 days. Sampling for cell counting by flow cytometry was performed every 3 days for the first 24 days and then every 6 days till the end of the experiment. For transcriptome analysis of the $P$. minimum and $D$. shibae wildtype in co-culture, sampling was performed at day 18 , day 24 , and day $30.50 \mathrm{ml}$ of the cultures were pelleted at $5000 \mathrm{rpm}$

\section{TABLE 1 | Dinoroseobacter shibae strains used in this study.}

\begin{tabular}{lll}
\hline Strain & Description & Reference \\
\hline DFL-12 & Wild-type & Biebl et al., 2005 \\
$\Delta /$ lux| $\left.\right|_{1}$ & $\Delta /\left.u x\right|_{1}:: \mathrm{Gm}^{r}$ & Patzelt et al., 2013 \\
$\Delta c t r A$ & $\Delta c t r A:: \mathrm{Gm}^{r}$ & Wang et al., 2014b \\
$\Delta c c k A$ & $\Delta c c k A:: \mathrm{Gm}^{r}$ & Wang et al., 2014b \\
$\Delta 191-\mathrm{kb}$ & Plasmid-cured mutant & Ebert et al., 2013 \\
$\Delta$ fliC & Transposon mutant & Ebert et al., 2013 \\
$\Delta$ flgK & Transposon mutant & Ebert et al., 2013
\end{tabular}


for $10 \mathrm{~min}$ and transferred into $2 \mathrm{ml}$ Eppendorf tubes. The cell pellets were then covered with $1 \mathrm{ml}$ Trizol reagent (Ambion, Life Technologies, Carlsbad, CA, USA), snap frozen in liquid nitrogen and stored at $-70^{\circ} \mathrm{C}$ until RNA isolation. Two of the three samples were further used for RNA-seq analysis.

\section{RNA Isolation and Depletion of Ribosomal RNA}

The total RNA of $P$. minimum and D. shibae wild-type strain in co-culture was extracted according to (Wang et al., 2014a). PolyATract System IV (Promega, Madsion, WI, USA) was used for isolation of algal mRNA according to the manufacturer's instructions. For isolation of the bacterial mRNA Ribo-Zero Magnetic Kit for both plant leaf and gram-negative bacteria (Epicentre, Madsion, WI, USA) was used according to the manufacturer's instructions. The final purification of the eluted mRNA was performed using ethanol precipitation.

\section{RNA Sequencing and Data Analysis}

The library was prepared from ribosomally depleted total RNA using Scriptseq v2 RNA-Seq Library Preparation Kit (Epicentre, Madsion, WI, USA) following the manufacturer's protocol. Briefly, $50 \mathrm{ng}$ of ribosomally depleted total RNA was chemically fragmented. Reverse transcription was performed using random hexamers with a $5^{\prime}$ tail containing a unique tagging sequence. After cDNA synthesis, the terminal tagging oligonucleotide (TTO) that blocked the $3^{\prime}$ end was annealed to the $3^{\prime}$ end of the cDNA. Following extension with a DNA polymerase, a second, unique tagging sequence (complementary to the TTO) was added to the $3^{\prime}$ end of the cDNA. Purification of cDNA was done using Agencourt AMPure purification. The resulting di-tagged cDNA was amplified by PCR using primers that anneal to the two different tagging sequences on the cDNA to generate the library. Library purification was done using AMPure purification.

Libraries were assessed using the Agilent 2100 Bioanalyzer (Agilent Technologies, Santa Clara, CA, USA). For sequencing equal volumes of libraries (12 pM) were multiplexed on a single lane. Cluster generation was performed with cBot (Illumina, San Diego, CA, USA) using TruSeq SR Cluster Kit v3-cBot-HS (Illumina, San Diego, CA, USA). Sequencing was done on the HiSeq 2500 (Illumina, San Diego, CA, USA) using TruSeq SBS Kit v3 - HS (Illumina, San Diego, CA, USA) for 50 cycles. Image analysis and base calling were performed using the Illumina pipeline v 1.8 (Illumina, San Diego, CA, USA).

The sequencing output (50 bp single end short reads) of the Genome Analyzer IIx was controlled for general quality features using the fastq-mcf tool of ea-utils (http://code.google. $\mathrm{com} / \mathrm{p} /$ ea-utils) and was mapped against the genome sequence of D. shibae (NC_009952.1, NC_009955.1 NC_009956.1, NC_009957.1, NC_009958.1, and NC_009959.1) using BWA v 0.5.9-r16 (Li and Durbin, 2009). Statistical analysis of the mapped read counts was performed in the $\mathrm{R}$ environment using the package edgeR (Robinson et al., 2010). Gene set enrichment analysis for the cluster of orthologous (COG) group was performed based on the hypergeometric distribution function (phyper) in R. Raw and processed data are available from the gene expression omnibus database under accession number GSE55371.

\section{RESULTS}

\section{Transcriptome Changes of $D$. shibae during Growth in Co-culture with P. minimum}

In our previous work we demonstrated that population dynamics of $P$. minimum in the co-culture with $D$. shibae exhibited a mutualistic phase (day 1 to day 21 ) where both partners profit from each other and a pathogenic phase (day 21 to day 36) where $D$. shibae kills aging dinoflagellate cells (Wang et al., 2014a). In the same study we analyzed the influence of light on the transcriptome of $D$. shibae at an early stage (day 12) of the co-cultivation (Wang et al., 2014a). Here, we used RNA-sequencing of samples from the same co-cultivation experiment to analyze the transcriptome of $D$. shibae at three different growth stages: (1) day 18 when D. shibae was in the mid-exponential growth phase, while $P$. minimum had entered the stationary phase; (2) day 24 when $D$. shibae had entered the stationary phase, while $P$. minimum started to decline; (3) day 30 when $P$. minimum had almost vanished, while D. shibae remained in the stationary phase (Figure 1). Two of the three biological replicate samples for each time point were used for RNA-seq analysis. The library sizes of the samples from different time-points increased with the increasing density of bacteria in the co-culture. Samples from day 18 reached only 15 and $139 \mathrm{k}$ unique mapping reads, while samples from later time-points reached more than one to five

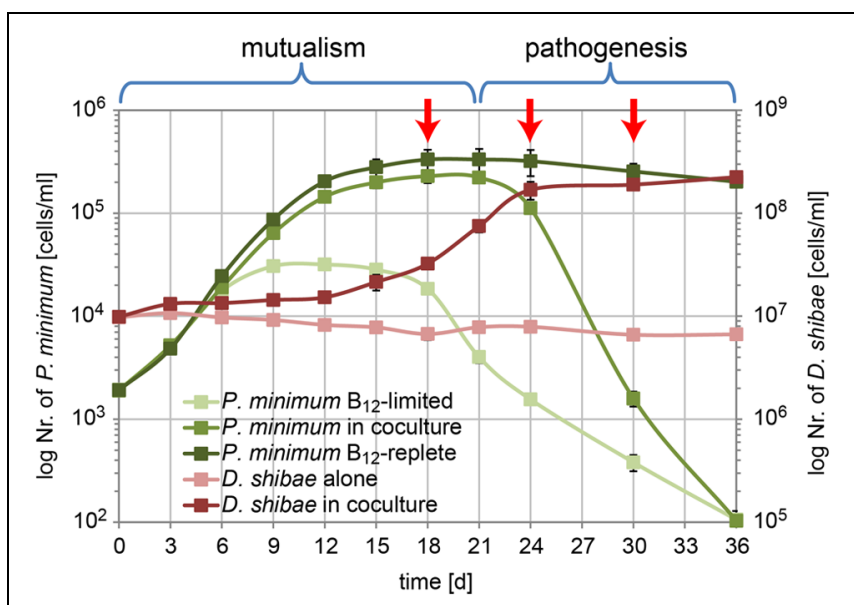

FIGURE 1 | Growth of $\boldsymbol{P}$. minimum and $\boldsymbol{D}$. shibae in co-culture. In the mutualistic phase (day 0-day 21) both organisms profit from the co-cultivation in a medium where the dinoflagellate and the bacterium are not able to grow in single culture due to lack of vitamin $B_{12}$ and organic carbon, respectively. In the pathogenic phase (day 21-day 36) the algae are killed by the bacteria, which continue to grow. Red arrows indicate the sampling time points for transcriptome analysis (modified from Wang et al., 2014a). 
million unique mapping reads (Supplementary Table S1). Despite these differences in sequencing depth the correlation between replicates was satisfactory for all time-points (Supplementary Figure S1A). To determine a cut-off for reliable changes in gene expression we reduced the sequencing depth for day 24 and day 30 to $100 \mathrm{k}$ reads by resampling. The deviation in expression and $\log _{2}$ fold-change between the reduced and original dataset strongly increased for genes with an abundance of $\log _{2} \mathrm{cpm}$ (counts per gene per million reads) lower than seven. We defined this value as the lower cut-off for reliable gene expression at day 18 (Supplementary Figures S1B,C). Only four of the 41 genes identified as significantly differentially expressed had a cpm-value slightly below this cut-off and therefor have to be treated with caution. This is consistent with our previous study, showing that small library sizes increase the error of the obtained reads per gene in particular for weakly expressed genes (Wang et al., 2014a).

Comparing day 24 to day 18 we observed 41 of the 4192 protein-coding genes with a significant differential expression, 15 of them up- and 26 down-regulated. This number most likely underestimates the true number of differentially expressed genes because of the low sequencing depth at day 18. In contrast, we found 391 differentially expressed genes for the comparison of day 30 with day 24, 146 of them up- and 245 downregulated. Both comparisons shared 17 differentially expressed genes (Figure 2A). The complete dataset can be found in Supplementary Table S2.

Interestingly, genes that had previously been identified as being part of the quorum-sensing controlled CtrA-phosphorelay (Wang et al., 2014b), were regulated in different directions during the two transitions analyzed here (Figure 2B). Specifically, when comparing the samples of day 24 to day $18, \operatorname{ctr} A$ and its targets, the $\operatorname{lux} R_{2} I_{2}$ operon coding for an autoinducer synthase and the respective transcription factor of the QS system, the sigma-factorantagonist $r b s W$ and its repressor $r b s V$ (Dshi_0072/73), genes controlling cyclic di-GMP, Dshi_0329/2814/2815/2820/3065 and other regulatory genes (Dshi_0123/0211/0212/0765) as well as the first gene of a Type II secretion locus (Dshi_1120) were consistently up-regulated. Moreover, the genes coding for components of the flagella, most of them located in three different clusters on the chromosome of D. shibae (Wang et al., 2014b), were all up-regulated.

When comparing day 30 (late pathogenic phase) to day 24 (early pathogenic phase), all of these genes were strongly and significantly down-regulated (Figure 2B). From the 391 differentially expressed genes found in this transition, 315 could be assigned to a COG category. Figure 2C shows that several COG categories were down-regulated, especially J (translation, ribosomal structure, and biogenesis), N (cell motility), T (signal transduction mechanisms), and $\mathrm{U}$ (intracellular trafficking, secretion, vesicular transport). By contrast, categories $\mathrm{K}$ (transcription), E (amino acid transport), and C (energy production) were higher expressed (Figure 2C). These data suggest that the cells had entered the stationary phase of growth at day 30. Since $D$. shibae is photoheterotrophic, and light has been shown to play an important role during adaptation to the stationary phase of growth (Soora et al., 2015), we had a closer look at genes important for photoheterotrophy (Figure 2C inset). Interestingly, two loci that have recently been associated with aerobic anoxygenic photosynthesis were up-regulated at this stage. The genes Dshi_2489-2595 might be involved in $\mathrm{CO}_{2}$ fixation and have previously been found to be permanently up-regulated in the light (Tomasch et al., 2011). The extrachromosomally located lpor gene codes for a functional light-dependent protochlorophyllide reductase of cyanobacterial origin (Kaschner et al., 2014). Its expression is controlled by light and nutrient limitation, and it is located on a $72 \mathrm{~kb}$ chromid which is indispensable for survival under starvation in the light (Soora et al., 2015). Thus, our data are in accordance with previous studies and suggest that $D$. shibae switches to a more photoheterotrophic lifestyle when substrates gained from the lysis of algae become scarce.

\section{Co-cultivation of $P$. minimum with D. shibae Knock-out Mutants}

To determine how the different genetic modules shown to be expressed in a growth-phase dependent way in the coculture of $D$. shibae with $P$. minimum influence mutualism or pathogenesis, we deleted key-genes and grew the respective mutants (Table 1) in co-culture with P. minimum. Deletion of the autoinducer synthase $\operatorname{LuxI}_{1}$ results in a QS null mutant which lacks morphological heterogeneity and down-regulated flagella synthesis and expression of the two T4SS (Patzelt et al., 2013). For the CtrA phosphorelay we studied deletions of the histidine kinase CckA $(\triangle c c k A)$ and of the response regulator CrtA (Wang et al., 2014b).The $\Delta c t r A$ mutant described previously had by chance lost the $191 \mathrm{~kb}$ plasmid (Wang et al., 2014b) and is therefore designated $\triangle c t r A-191$. Additionally we therefore investigated a mutant with intact $c r t A$ gene but lacking the $191 \mathrm{~kb}$ plasmid (designated $\Delta 191$; Ebert et al., 2013) that had been cured according to the strategy described (Petersen et al., 2012). For the components of the flagella, we used the structural genes $f l i C$ and $f l g K$ that had been deleted by transposon mutagenesis (Ebert et al., 2013). All of the strains were able to grow in single culture. $\Delta l u x I_{1}$ as well as $\Delta c c k A$ and $\Delta c t r A-191$ had a shorter lag phase and higher growth rate in artificial sea-water supplemented with succinate as c-source as reported before (Patzelt et al., 2013; Wang et al., 2014b). The same was true for both flagella mutants while the $\Delta 191$ mutant strain showed a prolonged lagphase and lower growth-rate in single culture (Supplementary Figure S2).

When the QS null mutant $\Delta l u x I_{1}$ was cultivated together with $P$. minimum (Figure $\mathbf{3 A}$ ) it grew faster than the wildtype, in accordance with its smaller cell size and higher growth rate in pure culture described previously (Patzelt et al., 2013). In contrast to the growth of the wild-type, cell numbers of the QS null mutant doubled within the first 3 days, even when cultivated alone in the medium without $\mathrm{C}$-source. In co-culture cell numbers doubled initially as well, but - like in the wild-type substantial growth started only at day 12 . From then on, the mutant grew marginally faster than the wild-type and it reached slightly lower final cell densities. Interestingly, the decrease in the cell numbers of $P$. minimum started 3 days earlier in co-culture 


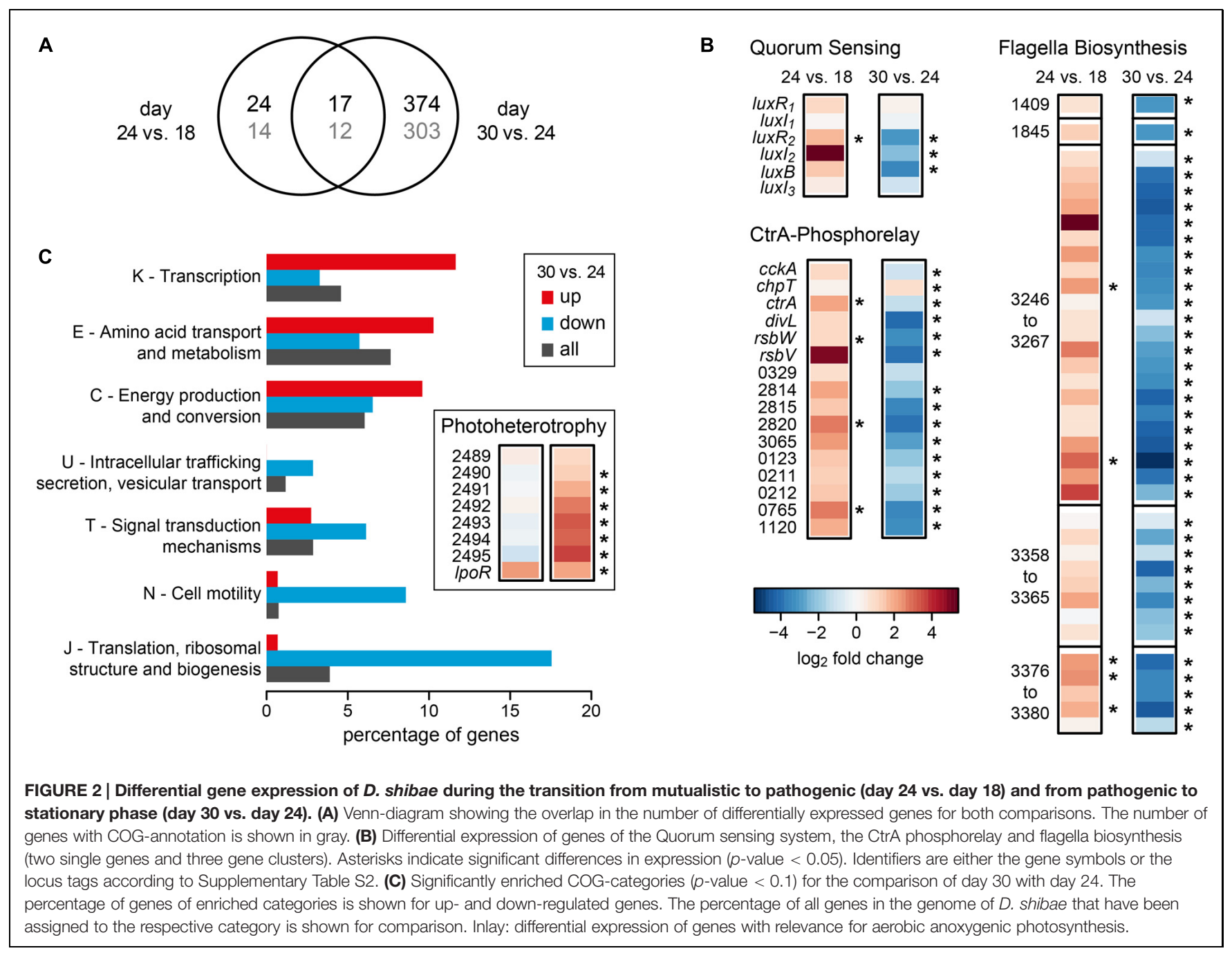

with the QS null mutant than in co-culture with the wild-type. The earlier start of the pathogenic phase might be a result of the faster growth rate of the QS null mutant and indicates a dosage effect, i.e., a larger number of cells has a stronger killing effect, in accordance with previous observations (Wagner-Döbler et al., 2010).

Next, we tested how the CtrA phosphorelay affects the interaction with the dinoflagellate (Figure 3B). The $\triangle c c k A$ knock-out strain, which lacks the histidine kinase required for phosphorylating CtrA, grew initially faster in co-culture than the wild-type but reached a lower final cell density, most likely because of lack of growth of the dinoflagellate. In this co-culture, the dinoflagellate showed only weak growth and started dying at day 18 , comparable to the negative control. These data suggest that the CtrA phosphorelay is critically important for establishing the mutualistic symbiosis between P. minimum and D. shibae.

The two strains lacking the $191 \mathrm{~kb}$ plasmid, $\Delta c t r A-191$ and $\Delta 191$, differed in their initial growth rates in co-culture, likely due to the presence or absence of the ctrA gene (Figure 3B). While $\Delta c t r A-191$ grew faster than the wild-type, similar to the $\triangle c c k A$ mutant, $\Delta 191$ grew just like the wild-type. However, both mutants completely lacked the ability to kill the dinoflagellate. These data prove that it is indeed an interaction with the bacteria that kills the algae. Moreover, they show that essential determinants of the pathogenicity of $D$. shibae toward the alga are located on the $191 \mathrm{~kb}$ plasmid.

Synthesis of flagella is controlled by CtrA in all Alphaproteobacteria studied so far (Greene et al., 2012). Furthermore, their role in attachment of Ruegeria sp. TM1040 to the surface of its dinoflagellate host has been demonstrated (Miller and Belas, 2006). Therefore we asked which role the flagella play for the interaction of D. shibae and P. minimum. We found that knockout of either the flagellin $(f l i C)$ or a flagella hook associated protein ( $f g K)$ led to reduced growth of the dinoflagellate in co-culture, comparable to the negative control (Figure 3C). This effect was even more pronounced than for the $\triangle c c k A$ mutant (Figure 3B). The dinoflagellate already died at day 15 , earlier than in the negative control, indicating that not only was the symbiosis not established, but the bacteria most likely actively killed cells of $P$. minimum. These data indicate that flagella have an important role in the interaction which is independent of the CtrA phosphorelay. 
A

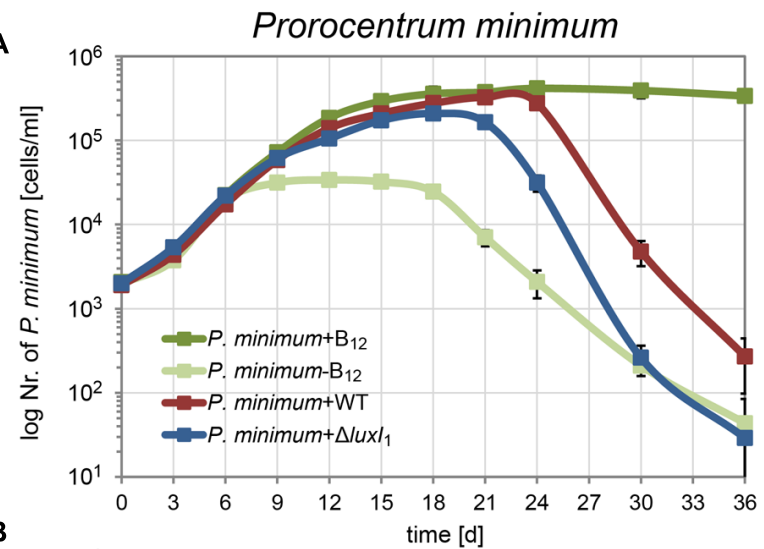

B

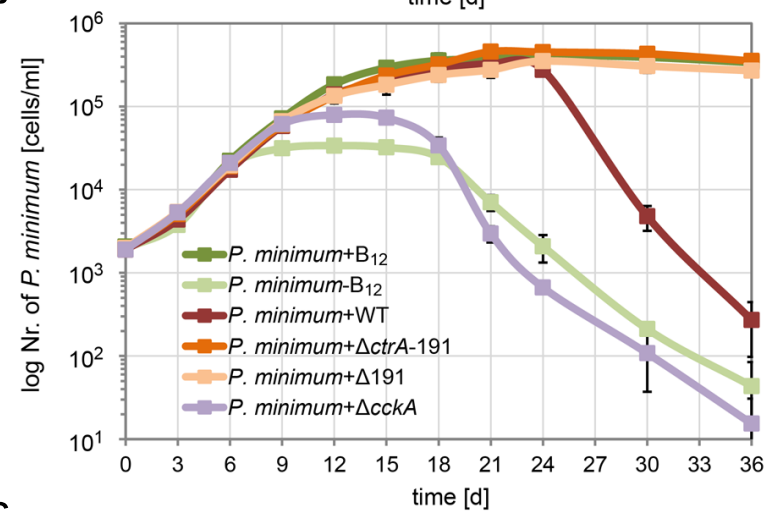

C

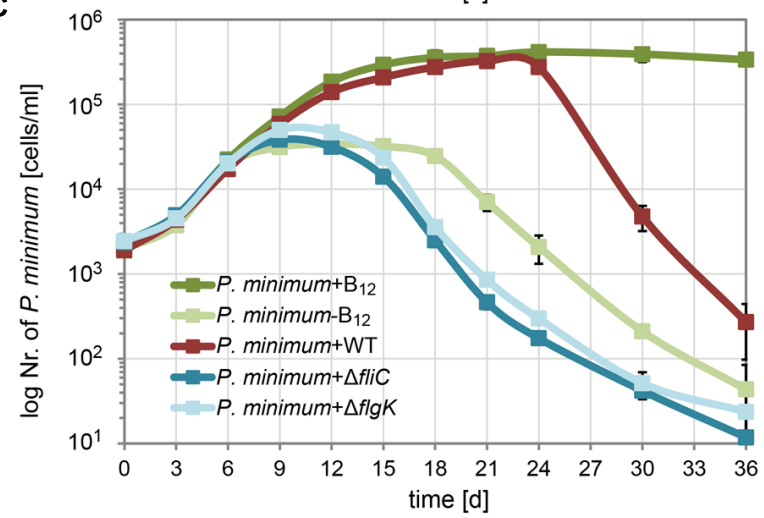

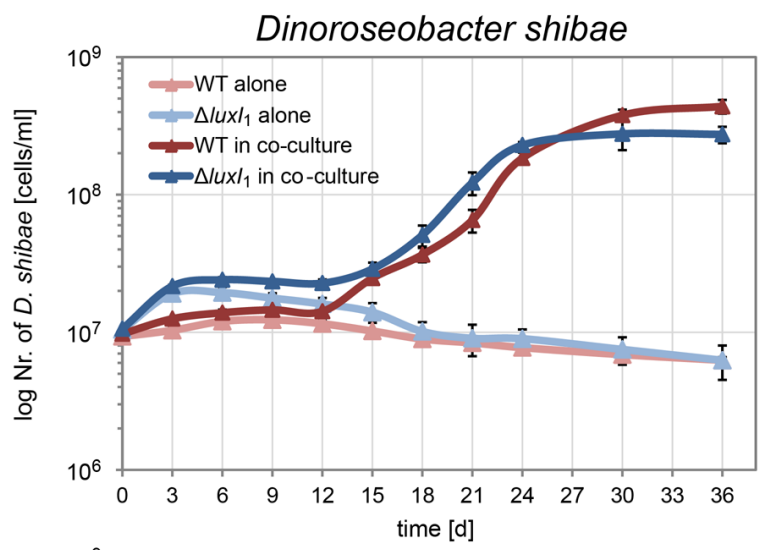
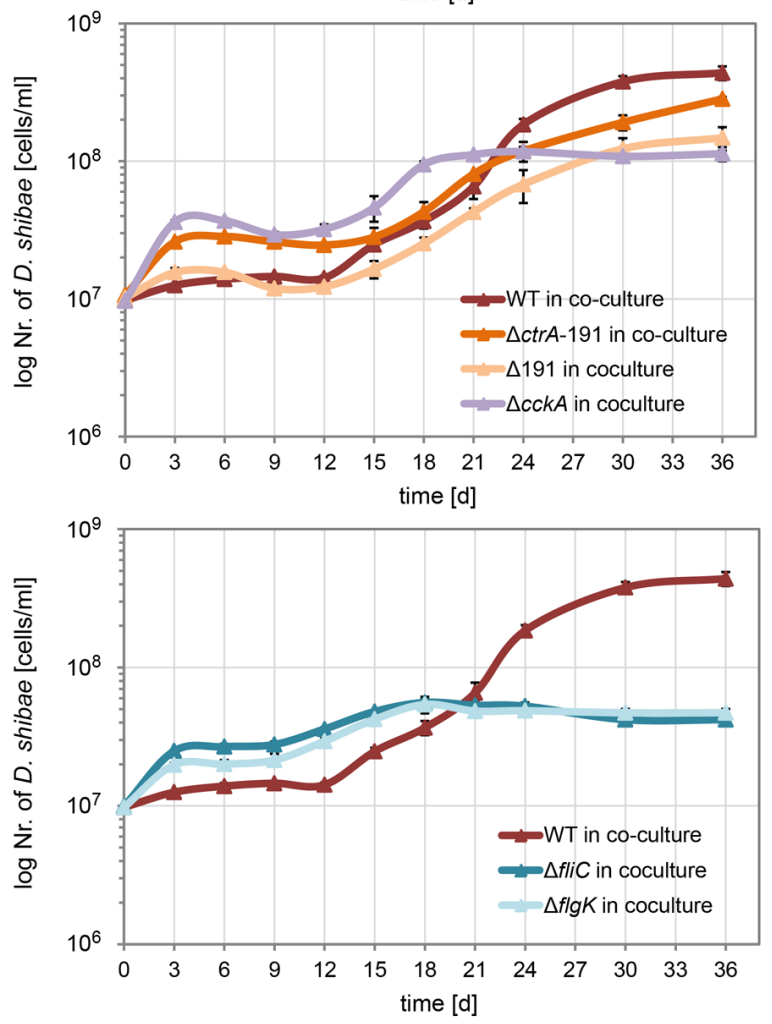

FIGURE 3 | Growth of $P$. minimum and different $\boldsymbol{D}$. shibae mutants in co-culture. $P$. minimum cell numbers are shown on the left, $D$. shibae cell numbers are shown on the right. The P. minimum positive and negative controls as well as the growth of the co-culture with wild-type $D$. shibae are shown in every panel for comparison. (A) Co-culture with the quorum sensing null-mutant $D$. shibae $\Delta /\left.u x\right|_{1}$, (B) with the phosphorelay knock-out mutants $D$. shibae $\Delta c c k A$ and $\Delta c t r A-191$, the latter additionally lacking the $191 \mathrm{~kb}$ plasmid, and a $\Delta 191 \mathrm{~kb}$ cured mutant with intact ctrA gene, (C) with $D$. shibae $\Delta$ fliC and $\Delta$ flik, lacking functional flagella. Data represent mean and standard deviation of three biological replicates.

\section{DISCUSSION}

Here, we show that QS, CtrA phosphorelay and flagella biosynthesis are regulated in opposite directions in different phases of the co-culture between $D$. shibae and P. minimum: at the onset of the pathogenic phase, those three traits are upregulated, while they are down-regulated in the late pathogenic phase which might resemble the stationary phase of growth for D. shibae. CtrA phosphorelay and flagella biosynthesis have been shown to be controlled by QS in D. shibae (Patzelt et al., 2013).
Expression of QS controlled genes can be density dependent, depending on the structure of the regulatory network (Fuqua et al., 1994; Haseltine and Arnold, 2008) and therefore their observed up-regulation during growth of $D$. shibae with the dinoflagellate could be unrelated to the co-cultivation. However, we previously showed that the QS controlled genes are not expressed in a density-dependent way when $D$. shibae is cultivated alone in a defined medium (Patzelt et al., 2013). Therefore, the transcriptome data suggest a possible role of QS, CtrA and flagella in the interaction of D. shibae with the dinoflagellate. 
The contribution of those traits toward mutualism or pathogenicity, respectively, was investigated by co-cultivating a number of different mutants of $D$. shibae with the dinoflagellate. We show that establishment of a mutualistic interaction required the CtrA phosphorelay and flagella. Loss of CckA or essential parts of the flagellum led to reduced growth stimulation of the dinoflagellate by the bacterium. The cell numbers did not exceed those of the negative control. Our data therefore confirm the important role of flagella for interaction with host organisms that has already been found for Ruegeria sp. TM1040 which actively swims toward algal products and uses flagella for attachment (Miller et al., 2004; Miller and Belas, 2006). In contrast to $D$. shibae, TM1040 does not possess a QS system. This demonstrates that the role of CtrA and its targets in co-culture is not necessarily dependent on cell-cell communication. Control of CtrA by QS similar to that of $D$. shibae has been found in the sponge-symbiont Ruegeria sp. KLh11 where QS activates flagellar motility while inhibiting biofilm formation and therefore might also be crucial for interaction with the host (Zan et al., 2012, 2013). Recently it has been demonstrated that nodule-specific cysteine-rich peptides produced by Medicago plant species induce the differentiation of intracellular Sinorhizobium meliloti cells into nitrogen-fixing bacteroids by disrupting the expression of cell-cycle regulators, among them CtrA, furthermore exemplifying its important role for bacterial interaction with host species (Penterman et al., 2014).

The most striking finding of our study is the essential role of the $191 \mathrm{~kb}$ plasmid for the pathogenicity of $D$. shibae. It is a "killer plasmid," since strains cured from this plasmid have

\section{REFERENCES}

Alavi, M., Miller, T., Erlandson, K., Schneider, R., and Belas, R. (2001). Bacterial community associated with Pfiesteria-like dinoflagellate cultures. Environ. Microbiol. 3, 380-396. doi: 10.1046/j.1462-2920.2001.00207.x

Allgaier, M., Uphoff, H., Felske, A., and Wagner-Döbler, I. (2003). Aerobic anoxygenic photosynthesis in Roseobacter clade bacteria from diverse marine habitats. Appl. Environ. Microbiol. 69, 5051-5059. doi: 10.1128/AEM.69.9.50515059.2003

Amin, S. A., Hmelo, L. R., van Tol, H. M., Durham, B. P., Carlson, L. T., Heal, K. R., et al. (2015). Interaction and signalling between a cosmopolitan phytoplankton and associated bacteria. Nature 522, 98-101. doi: 10.1038/nature14488

Ankrah, N. Y., Lane, T., Budinoff, C. R., Hadden, M. K., and Buchan, A. (2014). Draft genome sequence of Sulfitobacter sp. CB2047, a member of the Roseobacter clade of marine bacteria, isolated from an emiliania huxleyi bloom. Genome Announc. 2:pii:e01125-14. doi: 10.1128/genomeA.01125-14

Berger, M., Neumann, A., Schulz, S., Simon, M., and Brinkhoff, T. (2011). Tropodithietic acid production in Phaeobacter gallaeciensis is regulated by $\mathrm{N}$-acyl homoserine lactone-mediated quorum sensing. J. Bacteriol. 193, 6576-6585. doi: 10.1128/JB.05818-11

Biebl, H., Allgaier, M., Tindall, B. J., Koblizek, M., Lunsdorf, H., Pukall, R., et al. (2005). Dinoroseobacter shibae gen. nov., sp. nov., a new aerobic phototrophic bacterium isolated from dinoflagellates. Int. J. Syst. Evol. Microbiol. 55, 1089-1096. doi: 10.1099/ijs.0.63511-0

Brilli, M., Fondi, M., Fani, R., Mengoni, A., Ferri, L., Bazzicalupo, M., et al. (2010). The diversity and evolution of cell cycle regulation in alpha-proteobacteria: a comparative genomic analysis. BMC Syst. Biol. 4:52. doi: 10.1186/1752-05 09-4-52

Case, R. J., Longford, S. R., Campbell, A. H., Low, A., Tujula, N., Steinberg, P. D., et al. (2011). Temperature induced bacterial virulence and bleaching disease in completely lost the ability to kill P. minimum. This plasmid harbors a T4SS that might be able to transmit virulence factors to the host cell (Petersen et al., 2012). However, plasmid-located T4SS are commonly associated with conjugational DNA transfer (Christie et al., 2005; Smillie et al., 2010). Since the $126 \mathrm{~kb}$ sisterplasmid that also carries a T4SS apparently cannot complement the loss of the $191 \mathrm{~kb}$ plasmid, it could be hypothesized that those two T4SS are functionally different. Both T4SS were expressed but not up-regulated in the pathogenic phase of the co-culture with the dinoflagellate (Supplementary Table S2). Alternatively, other genes that are present on the $191 \mathrm{~kb}$ plasmid could be mediating the observed killing effect.

\section{ACKNOWLEDGMENTS}

This work was supported by the DFG in Transregio-SFB TR51. We are grateful to Richard Münch (Institute of Microbiology, Technical University Braunschweig) and Christoph Wittmann (Institute of Systems Biotechnology, University of the Saarland, Saarbrücken) for valuable discussions and advice. We thank Simone Heitkämper und Arne Cordsmeier for performing growth experiments of $D$. shibae in single culture.

\section{SUPPLEMENTARY MATERIAL}

The Supplementary Material for this article can be found online at: http://journal.frontiersin.org/article/10.3389/fmicb. 2015.01262

a chemically defended marine macroalga. Environ. Microbiol. 13, 529-537. doi: 10.1111/j.1462-2920.2010.02356.x

Chen, Z., Zhang, J., Lei, X., Lai, Q., Yang, L., Zhang, H., et al. (2015). Mameliella phaeodactyli sp. nov., a member of the family Rhodobacteraceae isolated from the marine algae Phaeodactylum tricornutum. Int. J. Syst. Evol. Microbiol. 65, 1617-1621. doi: 10.1099/ijs.0.000146

Christie, P. J., Atmakuri, K., Krishnamoorthy, V., Jakubowski, S., and Cascales, E. (2005). Biogenesis, architecture, and function of bacterial type IV secretion systems. Annu. Rev. Microbiol. 59, 451-485. doi: 10.1146/annurev.micro.58.030603.123630

Durham, B. P., Sharma, S., Luo, H., Smith, C. B., Amin, S. A., Bender, S. J., et al. (2015). Cryptic carbon and sulfur cycling between surface ocean plankton. Proc. Natl. Acad. Sci. U.S.A. 112, 453-457. doi: 10.1073/pnas.1413137112

Ebert, M., Laass, S., Burghartz, M., Petersen, J., Kossmehl, S., Wohlbrand, L., et al. (2013). Transposon mutagenesis identified chromosomal and plasmid genes essential for adaptation of the marine bacterium Dinoroseobacter shibae to anaerobic conditions. J. Bacteriol. 195, 4769-4777. doi: 10.1128/JB. 00860-13

Fernandes, N., Case, R. J., Longford, S. R., Seyedsayamdost, M. R., Steinberg, P. D., Kjelleberg, S., et al. (2011). Genomes and virulence factors of novel bacterial pathogens causing bleaching disease in the marine red alga Delisea pulchra. PLoS ONE 6:e27387. doi: 10.1371/journal.pone. 0027387

Fuqua, W. C., Winans, S. C., and Greenberg, E. P. (1994). Quorum sensing in bacteria: the LuxR-LuxI family of cell density-responsive transcriptional regulators. J. Bacteriol. 176, 269-275.

Gardiner, M., Thomas, T., and Egan, S. (2015). A glutathione peroxidase (GpoA) plays a role in the pathogenicity of Nautella italica strain R11 towards the red alga Delisea pulchra. FEMS Microbiol. Ecol. 91:pii:fiv021. doi: 10.1093/femsec/fiv021 
Geng, H., and Belas, R. (2010). Molecular mechanisms underlying Roseobacterphytoplankton symbioses. Curr. Opin. Biotechnol. 21, 332-338. doi: 10.1016/j.copbio.2010.03.013

Gonzalez, J. M., Simo, R., Massana, R., Covert, J. S., Casamayor, E. O., Pedros-Alio, C., et al. (2000). Bacterial community structure associated with a dimethylsulfoniopropionate-producing North Atlantic algal bloom. Appl. Environ. Microbiol. 66, 4237-4246. doi: 10.1128/AEM.66.10.4237-4246.2000

Greene, S. E., Brilli, M., Biondi, E. G., and Komeili, A. (2012). Analysis of the CtrA pathway in Magnetospirillum reveals an ancestral role in motility in alphaproteobacteria. J. Bacteriol. 194, 2973-2986. doi: 10.1128/JB.00170-12

Haseltine, E. L., and Arnold, F. H. (2008). Implications of rewiring bacterial quorum sensing. Appl. Environ. Microbiol. 74, 437-445. doi: 10.1128/AEM.01688-07

Johnson, M. D. (2015). Inducible Mixotrophy in the Dinoflagellate Prorocentrum minimum. J. Eukaryot. Microbiol. 62, 431-443. doi: 10.1111/jeu.12198

Kaschner, M., Loeschcke, A., Krause, J., Minh, B. Q., Heck, A., Endres, S., et al. (2014). Discovery of the first light-dependent protochlorophyllide oxidoreductase in anoxygenic phototrophic bacteria. Mol. Microbiol. 93, 1066-1078. doi: $10.1111 / \mathrm{mmi} .12719$

Li, H., and Durbin, R. (2009). Fast and accurate short read alignment with burrows-wheeler transform. Bioinformatics 25, 1754-1760. doi: 10.1093/bioinformatics/btp324

Miller, T. R., and Belas, R. (2004). Dimethylsulfoniopropionate metabolism by Pfiesteria-associated Roseobacter spp. Appl. Environ. Microbiol. 70, 3383-3391. doi: 10.1128/AEM.70.6.3383-3391.2004

Miller, T. R., and Belas, R. (2006). Motility is involved in Silicibacter sp. TM1040 interaction with dinoflagellates. Environ. Microbiol. 8, 1648-1659. doi: 10.1111/j.1462-2920.2006.01071.x

Miller, T. R., Hnilicka, K., Dziedzic, A., Desplats, P., and Belas, R. (2004). Chemotaxis of Silicibacter sp. strain TM1040 toward dinoflagellate products. Appl. Environ. Microbiol. 70, 4692-4701. doi: 10.1128/AEM.70.8.46924701.2004

Patzelt, D., Wang, H., Buchholz, I., Röhde, M., Gröbe, L., Pradella, S., et al. (2013). You are what you talk: quorum sensing induces individual morphologies and cell division modes in Dinoroseobacter shibae. ISME J. 7, 2274-2286. doi: 10.1038/ismej.2013.107

Paul, C., and Pohnert, G. (2011). Interactions of the algicidal bacterium Kordia algicida with diatoms: regulated protease excretion for specific algal lysis. PLoS ONE 6:e21032. doi: 10.1371/journal.pone.0021032

Penterman, J., Abo, R. P., De Nisco, N. J., Arnold, M. F., Longhi, R., Zanda, M., et al. (2014). Host plant peptides elicit a transcriptional response to control the Sinorhizobium meliloti cell cycle during symbiosis. Proc. Natl. Acad. Sci. U.S.A. 111, 3561-3566. doi: 10.1073/pnas.1400450111

Petersen, J., Brinkmann, H., Bunk, B., Michael, V., Pauker, O., and Pradella, S. (2012). Think pink: photosynthesis, plasmids and the Roseobacter clade. Environ. Microbiol. 14, 2661-2672. doi: 10.1111/j.1462-2920.2012.02806.x

Riclea, R., Gleitzmann, J., Bruns, H., Junker, C., Schulz, B., and Dickschat, J. S. (2012). Algicidal lactones from the marine Roseobacter clade bacterium Ruegeria pomeroyi. Beilstein J. Org. Chem. 8, 941-950. doi: 10.3762/bjoc.8.106

Riemann, L., Steward, G. F., and Azam, F. (2000). Dynamics of bacterial community composition and activity during a mesocosm diatom bloom. Appl. Environ. Microbiol. 66, 578-587. doi: 10.1128/AEM.66.2.578-587.2000

Robinson, M. D., McCarthy, D. J., and Smyth, G. K. (2010). edgeR: a Bioconductor package for differential expression analysis of digital gene expression data. Bioinformatics 26, 139-140. doi: 10.1093/bioinformatics/btp616

Seyedsayamdost, M. R., Carr, G., Kolter, R., and Clardy, J. (2011a). Roseobacticides: small molecule modulators of an algal-bacterial symbiosis. J. Am. Chem. Soc. 133, 18343-18349. doi: 10.1021/ja207172s

Seyedsayamdost, M. R., Case, R. J., Kolter, R., and Clardy, J. (2011b). The Jekylland-Hyde chemistry of Phaeobacter gallaeciensis. Nat. Chem. 3, 331-335. doi: 10.1038/nchem.1002

Seyedsayamdost, M. R., Wang, R., Kolter, R., and Clardy, J. (2014). Hybrid biosynthesis of roseobacticides from algal and bacterial precursor molecules. J. Am. Chem. Soc. 136, 15150-15153. doi: 10.1021/ja508782y
Smillie, C., Garcillan-Barcia, M. P., Francia, M. V., Rocha, E. P., and de la Cruz, F. (2010). Mobility of plasmids. Microbiol. Mol. Biol. Rev. 74, 434-452. doi: 10.1128/MMBR.00020-10

Soora, M., Tomasch, J., Wang, H., Michael, V., Petersen, J., Engelen, B., et al. (2015). Oxidative stress and starvation in Dinoroseobacter shibae: the role of extrachromosomal elements. Front. Microbiol. 6:233. doi: $10.3389 /$ fmicb. 2015.00233

Stoecker, D. K., Li, A., Coats, D. W., Gustafson, D. E., and Nannen, M. K. (1997). Mixotrophy in the dinoflagellate Prorocentrum minimum. Mar. Ecol. Prog. Ser. 152, 1-12. doi: 10.3354/meps152001

Sule, P., and Belas, R. (2013). A novel inducer of Roseobacter motility is also a disruptor of algal symbiosis. J. Bacteriol. 195, 637-646. doi: 10.1128/JB.01 777-12

Teeling, H., Fuchs, B. M., Becher, D., Klockow, C., Gardebrecht, A., Bennke, C. M., et al. (2012). Substrate-controlled succession of marine bacterioplankton populations induced by a phytoplankton bloom. Science 336, 608-611. doi: $10.1126 /$ science. 1218344

Tomasch, J., Gohl, R., Bunk, B., Diez, M. S., and Wagner-Döbler, I. (2011). Transcriptional response of the photoheterotrophic marine bacterium Dinoroseobacter shibae to changing light regimes. ISME J. 5, 1957-1968. doi: 10.1038/ismej.2011.68

Tujula, N. A., Crocetti, G. R., Burke, C., Thomas, T., Holmstrom, C., and Kjelleberg, S. (2010). Variability and abundance of the epiphytic bacterial community associated with a green marine Ulvacean alga. ISME J. 4, 301-311. doi: 10.1038/ismej.2009.107

Voget, S., Wemheuer, B., Brinkhoff, T., Vollmers, J., Dietrich, S., Giebel, H. A., et al. (2015). Adaptation of an abundant Roseobacter RCA organism to pelagic systems revealed by genomic and transcriptomic analyses. ISME J. 9, 371-384. doi: 10.1038/ismej.2014.134

Wagner-Döbler, I., Ballhausen, B., Berger, M., Brinkhoff, T., Buchholz, I., Bunk, B., et al. (2010). The complete genome sequence of the algal symbiont Dinoroseobacter shibae: a hitchhiker's guide to life in the sea. ISME J. 4, 61-77. doi: 10.1038/ismej.2009.94

Wang, H., Tomasch, J., Jarek, M., and Wagner-Döbler, I. (2014a). A dual-species co-cultivation system to study the interactions between Roseobacters and dinoflagellates. Front. Microbiol. 5:311. doi: 10.3389/fmicb.2014.00311

Wang, H., Ziesche, L., Frank, O., Michael, V., Martin, M., Petersen, J., et al. (2014b). The CtrA phosphorelay integrates differentiation and communication in the marine alphaproteobacterium Dinoroseobacter shibae. BMC Genomics 15:130. doi: 10.1186/1471-2164-15-130

Wemheuer, B., Gullert, S., Billerbeck, S., Giebel, H. A., Voget, S., Simon, M., et al. (2014). Impact of a phytoplankton bloom on the diversity of the active bacterial community in the southern North Sea as revealed by metatranscriptomic approaches. FEMS Microbiol. Ecol. 87, 378-389. doi: 10.1111/1574-6941.12230

Zan, J., Cicirelli, E. M., Mohamed, N. M., Sibhatu, H., Kroll, S., Choi, O., et al. (2012). A complex LuxR-LuxI type quorum sensing network in a roseobacterial marine sponge symbiont activates flagellar motility and inhibits biofilm formation. Mol. Microbiol. 85, 916-933. doi: 10.1111/j.1365-2958.2012.08149.x

Zan, J., Heindl, J. E., Liu, Y., Fuqua, C., and Hill, R. T. (2013) The CckAChpT-CtrA phosphorelay system is regulated by quorum sensing and controls flagellar motility in the marine sponge symbiont Ruegeria sp. KLH11. PLoS ONE 8:e66346. doi: 10.1371/journal.pone.0066346

Conflict of Interest Statement: The authors declare that the research was conducted in the absence of any commercial or financial relationships that could be construed as a potential conflict of interest.

Copyright (c) 2015 Wang, Tomasch, Michael, Bhuju, Jarek, Petersen and WagnerDöbler. This is an open-access article distributed under the terms of the Creative Commons Attribution License (CC BY). The use, distribution or reproduction in other forums is permitted, provided the original author(s) or licensor are credited and that the original publication in this journal is cited, in accordance with accepted academic practice. No use, distribution or reproduction is permitted which does not comply with these terms. 